\title{
LEGISLACIÓN ROMANA Y LIBERACIÓN FEMENINA: UNA RELACIÓN INCONSCIENTE*
}

\author{
ARCADIO DEL CASTILLO \\ Universidad de Alicante
}

\begin{abstract}
Este estudio tiene como objetivo un intento deplasmar la incidencia que la normativa jurídica romana tuvo en la consecución a lo largo del tiempo de mayores cotas de libertad por parte del elemento femenino: ello se manifiesta de forma muy especial en ciertos aspectos como la legislación matrimonial, la ley sobre el adulterio, la tutela mulieris o el régimen dotal.

The object of this article is to attempt to assess the impact of Roman Law in the gradual conquest by women of greater rights and freedom. This development is especially evident in such matters as marriage Laws, the Law concerning adultery, the tutela mulieris or the dowry rights.
\end{abstract}

Una de las características más sobresalientes que hemos encontrado, no sin sorpresa, en todo el proceso, ya largo, de estudio de la situación de la mujer en época romana es la enorme incidencia que el desarrollo de la normativa legislativa romana ha desempeñado en el lento pero inexorable camino tendente hacia una mayor libertad femenina y que se concreta muy especialmente en la consecución de unas más amplias posibilidades sobre todo en lo que se refiere al manejo de su propia situación en el aspecto económico. Cuando los juristas romanos reconocen que en muchos extremos del Derecho era peor la condición de las hembras que la de los varones (1) estaban ya poniendo de manifiesto que dentro del sistema legislativo romano no se cumplía

(1) Dig. I, 5, 9: In multis iuris nostris articulis deterior est conditio feminarum quam masculorum. la idea de que la ley ha de ser igual para todos, que debe cubrir a todas las personas y todas ellas igualmente deben ser tratadas por ella de la misma forma, pero también connotaban algo extremadamente interesante como es el reconocimiento interno de un error que se pretendía o se suponía que se debería subsanar. Algunas normas jurídicas que se han supuesto dirigidas particularmente contra el sexo femenino, examinadas con una cierta cautela y sin apasionamiento, pueden ser explicadas desde un diferente punto de vista y por ello sin que se observe la aparición de ninguna pretensión concreta dirigida a estigmatizar a las mujeres y únicamente a las mujeres; en este sentido, se puede argumentar que

$\left.{ }^{*}\right)$ Texto de la ponencia leída el día 6 de julio de 1988 en la sesión del I Congreso Internacional de Historia de la Mujer celebrado en Alcalá de Henares. 
los romanos plantearon muy pocas veces leyes que se puedan considerar que hayan sido votadas exclusivamente contra las mujeres. Ciertas leyes como la Oppia sumptuaria del año 215 a. C., un plebiscito del tribuno C. Oppio contra el lujo de las mujeres prohibiéndoles llevar vestidos de variados colores y ornamentos de oro de un peso mayor de media libra, así como el uso en Roma de coches de dos caballos, y lo que ha sido considerado por algún autor moderno su posterior agravación en el año 210 a. C., la exhortación del cónsul Valerio Levino a los senadores para que diesen muestras de su patriotismo, entregando parte de sus propias fortunas al tesoro público pudiendo disponer de los anillos de oro de sus esposas e hijas, ejemplo que fue seguido igualmente por caballeros y plebeyos, según dice Tito Livio (XXVI, 36), la Orchia de coenis del año 181 a. C., un plebiscito del tribuno C. Orchio - plebiscito favorecido por Catón- por el que se fijaba un límite al número de los convidados en los banquetes, por lo que atacaba indirectamente a las mujeres, y la Voconia de mulierum hereditatibus del año 169 a. C., un plebiscito del tribuno Q. Voconio Saxa por el cual las mujeres no tenían derecho a ser instituidas como herederos en el testamento de los ciudadanos censados en la primera de las clases, todas ellas interpretadas generalmente como dirigidas claramente contra las mujeres, realmente tienen un planteamiento que apunta mayormente una tendencia hacia la generalización, en el sentido de:

a) Acabar con el lujo: Que las mujeres sean las más atacadas podría deberse a una cierta tendencia a suponerlas portadoras de un cierto espíritu amante de lo lujoso, lo que es algo que no podía obviar fácilmente la mente de los legisladores, pero atacar el lujo excesivo parece la tendencia general. Para èllo se pueden argumentar toda una serie de leyes suntuarias (por orden cronológico: Fannia, Didia, Aemilia, Licinia, Cornelia, Antia o las dos Iuliae), que no se dirigen expresamente contra las mujeres. Por otra parte, hay que tener en cuenta el hecho manifiesto de encontrarse Roma en el peligro de la guerra con Aníbal, por lo que exigir una cierta ponderación en los gastos o lo que es lo mismo, escatimar las exhibiciones de riqueza en un momento de escasez no parece desorbitado.

b) Restaurar las viejas costumbres: Así, por ejemplo, el testamento en sus orígenes tenía un carácter de Derecho Público, puesto que tenía por objeto el nombrar un nuevo paterfamilias, pero si por medio testamentario se nombraban herederos, al margen del paterfamilia, éste tendía a convertirse en un título sin fuerza que podía ser rechazado.

En todas estas leyes existe un componente claro de defensa de la vieja tradición romana en cuanto al recato de las costumbres $\mathrm{y}$, como consecuencia de ello, según ha mantenido C. Herrmann, otro componente importante que tiene que ver con el mantenimiento de las prácticas religiosas de tipo tradicional concretadas en la Religión Oficial frente a la entrada, demasiado bien acogida por las mujeres, de los cultos de tipo oriental, de los cultos de tipo mistérico. El levantamiento, incluso a veces violento, de las mujeres contra la ley Oppia en concreto, lo que apoyó su abrogación mediante la ley $\mathrm{Va}$ leria Fundania de lege Oppia sumptuaria abrogan$d a$ del año 195 a. C., un plebiscito de los tribunos L. Valerio y M. Fundanio - pese a la clara oposición de la facción dirigida por Catón-, no tendría sentido, según la misma investigadora citada anteriormente, sin el componente religioso contrario a las viejas costumbres, que quedó plasmado palmariamente en el caso de la represión de las Bacanales del año 186 a. C.; y quizá también porque detrás de un problema religioso casi siempre late con fuerza un planteamiento político que amenaza de forma directa al propio Estado. Por otra parte, en la mayoría de las ocasiones en las que la legislación romana parece tender a desfavorecer a la parte femenina, se podría decir con grandes posibilidades de acierto que está pesando como una enorme losa la idea, naturalmente equivocada, pero asumida sincera y confiadamente por los juristas romanos, de que la debilidad propia del sexo femenino hacía que las mujeres se viesen expuestas a mayores posibilidades de engaño, por lo que debían de ser protegidas declinando la responsabilidad de las decisiones en alguien al margen de ellas mismas. No es nuestro deseo, sin embargo, ocultar lo que de negativo hacia las mujeres aparece igualmente constatado por decisiones jurídicas; existen en el terreno legislativo, desde luego, puntos difícilmente asumibles. Es claro que las mujeres romanas carecieron siempre de derechos de tipo político y los juristas no se lamentaron nunca de ello ni tampoco pretendieron acabar con semejante situación. E igual sucede con ciertas profesiones, que no podían ser desempeñadas por las mujeres, y así ocurre que no podían ser banqueros (2),

(2) Dig. II, 13, 12: Feminae remotae videntur ab officio ar gentarii quum ea opera virilis sit. 
ni tampoco ser jueces, ni tener magistratura, ni actuar como abogadas, ni intervenir en representación de alguien, ni ser procuradoras (3) y el Senatus consultum Velleianum, probablemente del año $46 \mathrm{~d}$. C. (PAUL., Sent. II, 11, 1; Dig. XII,16, 40; XVI, 1; XLVI, 1, 3; Cod. Iust. IV, 29), estableció para las mujeres la prohibición de intercedere pro aliis, con lo que decretó la nulidad de las obligaciones derivadas de fianzas y préstamos asumidas por mujeres como intercesión en beneficio de otros (Dig. XVI, 1, 2, 1), con la excepción de que la mujer actuase en beneficio propio ( $D i g . X V I, 1,13 ; 15 ; 21$; $22 ; 25,1 ; 27,2 ; 32$ ) o estuviese claro que había actuado maliciosamente con ánimo de engañar (Dig. $\mathrm{XVI}, 1,2,3)$. La base para todos estos impedimentos está en la idea romana de que ciertas ocupaciones eran en sí mismas oficios civiles, reservados por las antiguas costumbres para ser desempeñados exclusivamente por los varones.

Ahora bien, al margen de esto, lo cierto es que existe un amplio desarrollo legislativo que ha tendido a atenuar las dificultades en el camino de la mujer romana hacia la consecución de mayores cotas de libertad en determinados campos de actuación y que debe ser tenido en cuenta, sobre todo porque se trata de un proceso en el que, normalmente, no han intervenido las mujeres, sino que son los elementos del sexo contrario los que parece han tomado la iniciativa de terminar o cambiar ciertos aspectos legislativos que se traducían en claras injusticias; las normas jurídicas han ido paso a paso permitiendo a las mujeres un más extenso ámbito de libertad, de control de intereses propios, y ello se realiza generalmente de espaldas a las mismas mujeres, aunque después ellas, o mejor una parte de ellas, supiesen usar de estos nuevos caminos, que el proceso legislativo había venido a abrirles, para conseguir una serie de derechos que, hasta entonces, les eran negados y realizar una serie de actos a los que, sin la existencia de esas nuevas normas, no hubieran tenido acceso.

\section{LEGISLACION MATRIMONIAL}

Ciertamente que existen ejemplos en los que la normativa jurídica, que termina por favorecer a la

(3) Dig. L, 17, 2: Feminae, ab omnibus officis civilibus, vel publicis remotae sunt; et ideo nec iudices esse possunt, nec magistratum gerere, nec postulare, nec pro alio intervenire, nec procuratores existere. mujer, no ha tenido semejante hecho como factor decisivo, como idea motriz de su promulgación, sino como algo colateral dentro de un contexto en el que se pretendian conseguir otros fines mucho más amplios. Tal sucede con la legislación matrimonial de Augusto y su desarrollo posterior. El emperador Augusto por medio de la ley Iulia et Papia Poppaea del año $9 \mathrm{~d}$. C. - - se trata realmente de la refundición de dos leyes, la lex Iulia de maritandis ordinibus y la lex Papia Poppaea nuptialis, cuya unión, por reproducir la segunda la mayoría de las disposiciones de la anterior, fue tan perfecta que pasaron a ser designadas en forma conjunta como una sola ley-, cuyo propósito legislativo era el fortalecimiento de la alicaída familia romana, concedía.recompensas y privilegios a quienes se casasen y tuviesen una familia numerosa y penaba, en cambio, a los célibes - caelibes - y a los que estando casados no tenían hijos - orbi- y en su interés por aumentar el número de nacimientos tendió igualmente a conceder algunos derechos a cierto número de mujeres que cumpliesen un requisito imprescindible, a saber, ser portadoras del ius liberorum, esto es el privilegio concedido a la mujer libre de nacimiento que tuviese tres hijos o a la manumitida con cuatro - y a partir de una constitución de Honorio y Teodosio del año $410 \mathrm{~d}$. C. a todas las mujeres, con lo que el privilegio desaparece-; a tales mujeres se les otorgaba una situación de favor con respecto a las demás:

a) La liberación de la tutela perpetua de la mujer (GAYO, I, 145; 194; III, 44; ULP., Reg. XXIX, 3; CASS. DIO, LV, 2, 5 y LVI, 10, 2-3): Con lo que, de hecho, venía a disponer de su persona con una libertad de acción igual a la del varón, teniendo asimismo la capacidad para hacer testamento, y decidiendo abiertamente con respecto a sus bienes, su patrimonio, con absoluta libertad.

b) El derecho a recibir herencias o legados sin restricción alguna: O lo que es lo mismo, encontrarse exentas de las medidas establecidas por la lex Voconia de mulierum hereditatibus (tal parece la lógica explicación para Gnomon del Idios Logos, 28; igualmente lo sugiere CASS. DIO, LVI, 10, 2) de la que ya hemos hablado con anterioridad. En cualquier forma, como ya hemos apuntado en trabajos previos, esta ley perdió su significación durante la época imperial como consecuencia del desuso del censo y además fue burlada ya desde su promulgación, puesto que la persona que quería hacer un legado a una mujer podía optar por realizarlo recu- 
rriendo al sistema de los fideicommissa, esto es la liberalidad a título particular mortis causa como un encargo a una persona, fiduciarius, de transmitir toda o una cuota parte de los bienes que integraban su sucesión en favor de un tercero, fideicommissarius, cuyo cumplimiento dependía únicamente de la buena voluntad de esa persona que recibía la sucesión grabada con el fideicomiso. Cuando en tiempos del emperador Vespasiano el Senatus consultum Pegasianum declaró las leyes de Augusto aplicables igualmente a las sucesiones y legados realizados mediante fideicomisos (GAYO, II, 286 y 286a) es obvio que no se pretendía con ello el perjudicar únicamente a las mujeres, sino a todos los que se encontraban entre los penados por estas leyes, los caelibes y los orbi.

c) Heredar a sus hijos a título legítimo cuando morían intestados: Esta herencia no correspondía a la madre por la ley de las XII Tablas, pero el Senatus consultum Tertullianum de época del emperador Adriano hizo heredera a la madre en concurso con las hermanas consanguíneas, esto es, siempre que los referidos hijos no dejasen hijos herederos por derecho propio, ni padre al cual corresponda por ley la herencia o la posesión de los bienes, ni hermano consanguíneo (ULP., Reg. XXVI, 8; Dig. XXXVIII, 17; Cod. Iust. VI, 57, 6; 58, 14; VIII, 59, 2; Inst. III, 3, 2).

\section{LEX IULIA DE ADULTERIIS}

Algo parecido se puede concluir con respecto a la ley Iulia de adulteriis coercendis, propuesta por el emperador Augusto, que terminó también por favorecer a la mujer de una forma colateral, puesto que sustituyendo la legislación familiar por un auténtico procedimiento legal, convirtió el adulterio en un delito público e impidió que la mujer fuese castigada de una manera indiscriminada, como ocurría anteriormente; el delito debería ser comprobado y además se permitía exclusivamente al padre, y no al esposo, el derecho para utilizar el ius occidendi, siempre que fuera delito flagrante y hubiera ocurrido en su propia casa o en la de su yerno (Dig. XLVIII, 5, 23, 2 y 4; PAUL., Sent. II, 26, 1). En el caso que fuese el esposo el implicado en adulterio ciertamente que no era castigado - solamente de estupro si lo hubiera realizado con mujer honesta, Dig. XLVIII, 5,35 y $35,1-$, pero la esposa podía recurrir al divorcio y exigir la devolución íntegra de su dote (ULP., Reg. VI, 13).
En cambio hay otros ejemplos en los que la puesta en práctica de un cierto tipo de preceptos legislativos o el mismo desarrollo de algunos podrían dar la impresión de tener, seguramente sin pretenderlo abiertamente, como último fin el conseguir una posición favorecedora de la mujer, lo que desde luego se consiguió plenamente. Tienen, a nuestro entender, este carácter una serie de postulados que favorecen la capacidad de las mujeres fundamentalmente en el terreno económico por otorgarles una mayor libertad para poder disponer de su propio patrimonio. Se trata, como ya hemos apuntado en otro trabajo, de un terreno que si ro consigue otorgar la libertad absoluta a las mujeres, se puede afirmar que contribuye enormemente a colocarlas en la vía correcta, puesto que les confiere una capacidad muy grande al permitirles el uso de su patrimonio, lo que las libera de una manera absoluta de dependencias.

\section{CONVENTIO IN MANUM}

Ahora bien, el punto de arranque de todo el proceso legislativo que lleva hacia la libertad de la mujer romana en el terreno económico se encuentra en el desarrollo que tuvo el matrimonio en Roma y que llevó a la puesta en funcionamiento de la costumbre de contratar el matrimonio, pero sin efectuar al mismo tiempo la conventio in manum. Para los romanos el matrimonio era el medio para producir una unión con vistas a asegurar la procreación y la educación de los descendientes y la conventio in manum era el vehículo mediante el cual se conseguía introducir a la mujer en un grupo agnaticio diferente del suyo propio, poniéndola así bajo la autoridad del jefe de ese grupo; se trataba, por lo tanto, de dos caras diferentes de un proceso. Naturalmente la importancia del grupo agnaticio en los primeros tiempos era muy grande, por lo que resulta muy probable que en un comienzo el matrimonio se viese acompañado, de una manera generalizada, por la conventio in manum, pero con el paso del tiempo ésta fue perdiendo importancia y durante la etapa imperial se puede manifestar, sin temor a la equivocación, que esta institución se encuentra ya en trance de desaparición y la razón fundamental es que había dejado de ser interesante especialmente para el sexo femenino, debido a que la mujer, en un determinado momento, prefirió no pasar a depender de la familia del esposo y mantenerse dentro de su propia familia y bajo la autoridad de su paterfami- 
lias, autoridad que fue perdiendo su primitivo rigor para igualmente pasar a encontrarse, especialmente desde fines del período republicano, extremadamente debilitada. La primera manifestación de la tendencia hacia la desaparición con el tiempo del sometimiento de la mujer a la manus del esposo viene connotada por la introducción de la usurpatio trinoctii que quedó establecida mediante una disposición de la ley de las XII Tablas, como nos viene especificado por el jurisconsulto Gayo (4), lo que además aparece apoyado igualmente por Aulo Gelio (5), y este procedimiento vino a abrir el camino hacia la gran generalización para la contratación de matrimonios no acompañados de la conventio in manum que tendió a producirse en la sociedad romana. Lo cierto es que de las tres formas de contratar la conventio in manum, el usus es mencionado por última vez dentro de un contexto en Cicerón (pro Flacco XXXIV, 84) y Gayo $(\mathrm{I}, 111)$ lo da por desaparecido en su época, la coemptio, aunque Gayo (I, 113-114) considera que estaba en vigor en su época, la coemptio, aunque Gayo (I, 113114) considera que estaba en vigor en su época, hay que decir que no existe referencia segura de su aplicación con posterioridad a la Laudatio Turiae (I, 14-17) y la confarreatio, aunque dan muestra de su existencia Gayo (I, 112), Ulpiano (Reg. IX) y una inscripción de la época del emperador Cómmodo (CIL X, 6662 = ILS 1455), su uso era limitado, circunscribiéndose fundamentalmente a los cargos sacerdotales superiores, que únicamente podían ser designados de entre nacidos de nupcias confarreadas y la muestra de su desuso nos viene probada por la necesidad en la que se encontró Augusto de dar un Senatus consultum permitiendo a la flaminica Dialis estar sometida a la manus de su marido únicamente en las cosas sagradas, ante la dificultad para encontrar personas para el cargo (6), lo que fue después reforzado por Tiberio mediante una ley (7), tal

(4) GAYO, I, 111: Itaque lege XII tabularum cautum est, ut si qua nollet eo modo in manum mariti convenire, ea quotannis trinoctio abesset atque eo modo (usum) cuiusque anni interrumperet.

(5) AULO GELIO, N. A. III, 2, 13:...non enim posee impleri trinoctium, quod abesse a viro usurpandi causa ex Duodecim Tabulis deberet...

(6) GAYO, I, 136: (Praeterea mulieris quae in manum conveniunt, in patris potestate esse desinunt. Sed confarreatis nuptiis de flaminica Diali senatusconsulto ex relatione) Maximi et Tuberonis cautum est, ut haec quod ad sacra tantum videatur in manu esse, quod vero ad ce- vez la Asinia Antistia de flaminica Diali del año 24 d.C. En cualquier caso, la permanencia de la esposa en su propia familia, sin pasar a la del esposo, estableció la necesidad de concretar una separación de los bienes pertenecientes a ambos cónyuges $\mathrm{y}$, por lo tanto, la conclusión de que la mujer casada mantenía un patrimonio propio y al margen del marido, que no podía legalmente hacer uso de él.

Con semejante premisa, el proceso legislativo que lleva hacia la libertad económica de la mujer se centa en la liberación de la tutela mulieris y en la creación de medidas tendentes a la recuperación de la dote.

\section{TUTELA MULIERIS}

En su origen la tutela mulieris respondía al carácter del primitivo ordenamiento familiar, que se centraba en la autoridad del paterfamilias y que era ejercida sobre todos los miembros del grupo. Pues bien, encontrándose la mujer excluida de la potestad familiar dentro del sistema del régimen patriarcal imperante en la sociedad romana y limitándose su actuación al seno de la familia, se vio obligada a soportar una permanente tutela - con la excepción de las vírgenes Vestales, GAYO, I, 145- en todos los casos en los que no aparecía bajo la potestas de su paterfamilias o la manus de su marido; y, de esta manera, la tutela de la mujer venía a resultar a ser un medio para suplir la potestas del paterfamilias o la manus del esposo, con lo que mediante este sistema eran siempre otros los encargados de gestionar, al margen de la mujer, los bienes que eran propiedad de ella (cf. GAYO, I, 144; CIC., Mur. XII, 27; LIV., XXIV, 2). El tutor podía ser designado por el paterfamilias en su testamento, pero no existiendo testamento la tutela era ejercida por el agnado más mróximo; de ahí que en el primero de los casos estemos hablando de «tutela testamentaria» y en el segundo de «tutela legítima». La tutela legítima era irrenunciable, aunque admitía la posibilidad de ser cedida a otra persona mediante el acto jurídico de la in iure cessio tutelae (GAYO, I, 168-170; ULP., Reg. XI, 6-7) y por contra la tutela

teras causas proinde habeatur, atque si in manum non convenisset.

(7) TAC., Ann. IV, 16: ... lata lex qua flaminica Dialis sacrorum causa in potestate viri, cetera promisso feminarum iure ageret. 
testamentaria admitía la renuncia mediante otro acto jurídico denominado abdicatio tutelae (ULP., Reg. $\mathrm{XI}, 17)$. Por tanto, podían existir ocasiones en las que faltaba el tutor. Tal hecho produjo una novedad significativa que hizo que la fuerza de esta institución se tambalease, puesto que por medio de la ley Atilia de tutore dando - de fecha incierta, aunque nunca posterior al año $186 \mathrm{a}$. C. en que se produjo el primer ejemplo, LIV., XXXIX, 9- para Roma y la Iulia et Titia - posiblemente del año 32 a. C. - para las provincias se creó un nuevo tipo de tutela, tutela dativa (GAYO, I, 185; ULP., Reg. $\mathrm{XI}, 18$ ), bajo cuya influencia todas las demás se verán sensiblemente transformadas y mediante la cual en aquellos casos en los que faltaba el tutor, tanto legítimo como testamentario, su nombramiento era realizado en Roma por el pretor - a partir del emperador Claudio por los cónsules, SUET., Claud. XXIII, 2- y en las provincias por los gobernadores. Pero, éste era solamente el primer paso. Con el tiempo la antigua comunidad familiar fue tendiendo hacia la disgregación y, con ello, el régimen de la tutela fue igualmente perdiendo su razón de ser. La legislación fue arbitrando una serie de medidas que redujeron finalmente su eficacia y su aplicación. Una norma jurídica daba a las mujeres cuyo matrimonio estuviera acompañado de la conventio in manum la posibilidad otorgada por el marido para elegir a su tutor; se trataba de la denominada optio tutoris (GAYO, I, 150-154). Y los mismos juristas crearon un nuevo recurso, la coemptio tutelae evitandae causa (GAYO, I, 114-115), tomando el ejemplo de la tutela de los patronos sobre sus libertas, mediante el cual, de hecho, se permitía a las demás mujeres la elección de tutor haciendo que pudiesen eludir al que hasta entonces tenían. El método consistía en que la mujer hacía la coemptio, con la auctoritas de su tutor - que se salvaba generalmente mediante un pago - y luego el comprador la entregaba en propiedad a aquel que ella elegía, el cual a su vez la manumitía por vindicta y se convertía en su nuevo tutor, denominándose por ello tutor fiduciario (8). De esta manera, las mujeres pudieron disponer de tutores que, por varios motivos, se en-

(8) GAYO, I, 115: ... si qua velit quos habet tutores reponere, ut alium nanciscatur, illis auctoribus coemptionem facit: deinde a coemptinatore remancipata ei, cui ipsa velit, et ab eo vindicta manumissa incipit eum habere tutorem, quo manumissa est: qui tutor fiduciarius dicitur... contraban realmente controlados por ellas, con lo que tenían libertad absoluta para manejar sus patrimonios sin ningún problema. Existen ciertos ejemplos epigráficos que muestran de forma notoria este hecho al que nos estamos refiriendo. Así, en $C I L$ VI, 2650 una mujer llamada Furfania Saturnina hace la dedicatoria, entre otros, a su tutor M. Valerio Hesycho, que era un liberto de su esposo fallecido:

FVRFANIA. L. F. SATVRNINA / FECIT. SIBI. ET / A. MANNEIO. A. F. COL. CELSO. FILIO. SVO / MILITI. COHORTIS. VII. PRAETORIAE. ET / M. VALERIO. ISMARO. CONIVGI. SVO. ET / M. VALERIO. SEMNO. VERNAE. SVO. ET / M. VALERIO. ISMARI. L. HESYCHO. TVTORI. SVO. ET / SATVRNINAE. VENERIAE. VERNAE. SVAE. ET / EPICHARINI. LIBERTAE. ET / SECVNDAE. VENERIAE. VERNAE. SVAE / LIBERTIS. LIBERTABVS. POSTERISQ. EORVM / NATALI. VENERIAE. VERNAE. SVAE.

Y todavía resulta más definitivo el caso que aparece plasmado en $C I L$ VI, 7468, en donde Ostoria Acte lo dedica, también entre otros, a su tutor M. Ostorio Lamyro, muy posiblemente su propio liberto, a juzgar por el nombre:

D M / ISIDORO. QVI. ET. HERMIAE / LINTIARIO. OSTORIA. ACTE / VIRO. B. M. FECIT. ET. SIBI. ET. / T. CALESTRIO. HERMINO. FILIO. ET / M. OSTORIO. LAMYRO. TVTORI. SVO / ET. LIBERTIS. LIBERTAB. POSTERIS. Q. / EORVM. VTRIVSQ. SEXVS.

Por todo ello, se puede afirmar que después de los cambios relatados, la tutela ya no será obstáculo para la libre disposición de sus bienes, puesto que la mujer podía ya administrar sus propiedades y la función del tutor consistía simplemente en la interposición de su auctoritas cuando una transacción era considerada lesiva para la propiedad femenina. Es más, como afirma Gayo (II, 122), la mujer podía forzar al tutor a dar su auctoritas, incluso contra su propia voluntad, aunque siempre excluyendo a los tutores incluidos en la llamada tutela legítima. Por lo demás, la liberación de la tutela para las mujeres poseedoras del ius liberorum y la abolición de la tutela legítima de los agnados por el emperador Claudio, mediante la ley Claudia de tutela (ULP., Reg. XI, 8; GAYO, I, 157 y 171) contribuirán a dar el golpe definitivo a una institución que, aún per- 
durando, quedó desprovista de toda su fuerza, siendo únicamente un límite formal que la mujer podía superar con gran facilidad.

\section{DOTE}

Dentro de este recorrido por normas jurídicas que tienen la característica de posibilitar una mayor capacidad de las mujeres con respecto al uso de su patrimoio, nos queda por analizar aquellas que tienen que ver con el conjunto de bienes que eran transmitidos al esposo en el momento de contraer el matrimonio y que recibían el nombre de dote. Su importancia queda patentizada por ser, en opinión de M. García Garrido, «el ente patrimonial de mayor relevancia en el régimen de relaciones entre cónyuges». La costumbre impuso que, aunque la entrega de una dote no fuese absolutamente necesaria, ésta se encontrase unida al matrimonio. La dote, pues, aparece como la prueba más clara de la existencia de un matrimonio y de su honorabilidad, de forma que no existiendo éste, no había dote (Dig. XXIII, 3, 3 y 39, 1). Mientras que se mantuviese la unión matrimonial el esposo tenía a su cargo la administración de la dote y la esposa asumía una posición muy secundaria con respecto a ella. Y, aunque se exigía al esposo que fuese diligente en esa administración, respondiendo de la culpa si fuese mala (Dig. XXIII, 3, 17; XXIV, 1, 47 y 3, 66; XXV, 1, 15), también es cierto, como mantiene A. Watson, que cualquier deterioro de los bienes dotales era achacado a la mujer a menos que se pudiera probar la existencia de un fraude o una negligencia por parte del esposo.

En la introducción de la restitución de la dote influyó decisivamente, además de la costumbre de los matrimonios establecidos sin la conventio in manum, el desarrollo generalizado de la práctica del divorcio. Aulo Gelio nos comunica que Servio Sulpicio, escribiendo sobre la dote, manifestó que no habiendo sido nunca necesarias reglas establecidas con respecto a la dote aportada por la esposa a la hora de contraer matrimonio, el divorcio de Spurio Carvilio Ruga - producido hacia el año 231 a. C. debido a la esterilidad de su esposa- vino a establecer el que se impusiesen ciertas seguridades sobre el particular, con lo que desde entonces fue necesario el establecimiento de las cautiones rei uxoriae (9). Tales cautiones consistían en una previa estipulación al constituir la dote, en la que era acordado, entre otras cosas, la posible devolución de los bienes que la componían. Su cumplimiento se exigía por medio de la actio ex stipulatu, que sancionaba las promesas verbales (Dig. XXIII, 3, 13 y 63; $4,29,1$; XXIV, 3, 45). Ahora bien, la propia concepción que los romanos tenían del matrimonio, basado exclusivamente en la affectio maritalis, hacía el divorcio muy fácil, ya que bastaba con que la voluntad de los cónyuges de permanecer unidos se truncase para que el matrimonio quedase disuelto automáticamente; en tales casos, un simple aviso, el abandono del domicilio o, incluso, la contratación de un nuevo matrimonio, producían por sí mismos la rotura del vínculo matrimonial. Por todo ello, el divorcio tendió a generalizarse en la sociedad romana, con la particular novedad de que aparece con gran frecuencia el caso en el que es la mujer la que toma la iniciativa. Todo esto va a promocionar que el sistema inaugurado por las cautiones termine por desembocar en la creación de la actio rei uxoriae - para algunos mediante la lex Maenia de dote, tal vez del año 162 a. C.- que permitía tanto a la mujer, si era sui iuris, como a su paterfamilias solicitar la devolución de los bienes dotales incluso en el caso de que no se hubiera estipulado previamente su restitución (ULP., Reg. VI, 6; Dig. XXIII, 3, 24; 42; 52; 73; 5, 18; XXIV, 3, 2) y tanto por divorcio como por defunción del esposo; y únicamente podía el marido hacer retenciones de los bienes dotales cuando eran la mujer o su padre los culpables del divorcio (ULP., Reg. VI, 9-12). A ello hay que sumar que el emperador Augusto, mediante la denominada lex Iulia de fundo dotali -en realidad un capítulo de la lex Iulia de maritandis ordinibus-, prohibió al esposo la alienación de los bienes dotales inmuebles sin contar con el previo

(9) AULO GELIO, N. A. IV, 3, 1-2: Memoriae traditum est quingentis fere annis post Romam conditam nullas rei uxoriae neque actiones neque cautiones in urbe Roma aut in Latio fuisse, quoniam profecto nihil desiderabantur, nullis etiamtunc matrimoniis divertentibus. Servius, quoque Sulpicius in libro, quem composuit De Dotibus, tum primum cautiones rei uxoriae necessarias esse visas scripsit, cum Spurius Carvilius, cui Ruga cognomentum fuit, vir nobilis, divortium cum uxore fecit, quia liberi ex ea corporis vitio non gignerentur, anno urbis conditae quingentesimo vicesimo tertio $M$. Atilio, P. Valerio consulibus. Atque is Carvilius traditur uxorem quam dimisit egregie dilexisse carissimamque morum eius gratia habuisse, set iurisiurandi religionem animo atque amori praevertisse quod iurare a censoribus coactus erat, uxorem se liberum quaerundum gratia habiturum. 
consentimiento de la esposa (PAUL., Sent. II, 21b, 2; Dig. XXIII, 3, 32; 5, 4; Cod., Iust. V, 23, 1) y asimismo, mediante la lex Iulia de maritandis ordinibus, prohibió que el esposo pudiera manumitir a los esclavos dotales sin el permiso de la mujer, puesto que daba a ésta una acción para reclamar todo lo que se hubiera obtenido como consecuencia de la manumisión (Dig. XXIV, 3, 61-65). Estas medidas, unidas a otras, tales como que no se considerase que hubiera hurto si la mujer sustraía algunos de los bienes dotales durante el matrimonio, que los frutos de la dote pudieran invertirse en alimentos para la mujer sin incurrir en la prohibición de donaciones entre cónyuges, que la dote fuese excluida de la partición de la herencia del padre del esposo, reservándose a éste (Dig. X, 2, 20, 2 y 46) o que la dote fuese respetada a la hora de confiscar los bienes del marido (CASS. DIO, XLVIII, 8, 5), concluyen hacia la idea de la pertenencia de la dote a la mujer, como un paso más en la consecución de esa libertad económica de la que hemos venido hablando.

\section{BIBLIOGRAFIA}

ASTOLFI, R., La lex Iulia et Papia, Padova, 1970.

BALSDON, J. P. V. D., Roman Women. Their History and Habits, London, 1962.

BESNIER, R., «L'extension des lois caducaires aux fidéicommis d'aprés Gaius Institutes, II, 286 et 286a», Mélanges Henry Levy-Bruhl, Paris, 1959, págs. 25-28.

BIONDI, B., «La poena adulterii da Augusto a Giustiniano», Scritti di diritio e di economía in onore di Flaminio Mancaleoni, Sassari, 1938, págs. 63-96.

BONFANTE, P., Corso di diritto romano. $I$, Diritto di famiglia, reimp. Milano, 1963,

BRINI, G., Matrimonio e divorzio nel diritto romano, Bologna, 1887-89.

CASADO CANDELAS, M.J., La tutela de la mujer en Roma, Valladolid, 1972.

CASTILLO, A. del, «El papel económico de las mujeres en el Alto Imperio Romano», Revista Internacional de Sociologia XXXII, 1974, págs. 59-76.

- «Problemas en torno a la legislación matrimonial de Augusto», Hispania Antiqua IV, 1974, págs. 179-189.

- La emancipación de la mujer romana en el siglo I d. C., Universidad de Granada, 1976.

- «Sobre las formas de adquisición de la manus en el matrimonio», Anuario de Estudios Sociales y Jurídicos VI, 1977, págs. 359-365.

- «The position of women in the Augustan age», Liverpool Classical Monthly II, 1977, págs. 167-173.
- «Apuntes sobre la situación de la mujer en la Roma Imperial», Latomus XXXVIII, 1979, págs. 173-187.

- «El sistema legislativo como elemento fundamental para el desarrollo femenino en el mundo romano", Actas de las Quintas Jornadas de Investigación Interdisciplinaria (La mujer en el mundo antiguo), Universidad Autónoma de Madrid, 1986, págs. 183-193.

CORBETT, P.E., The Roman Law of Marriage, Oxford, 1930.

DIXON, S., «Infirmitas sexus: Womanly weakness in Roman Law», Tijdschrift voor Rechtsgeschiedenis LII, 1984, págs. 343-371.

DUMONT, F., «Les revenus de la dote en droit romain", $R \boldsymbol{e}$ vue Historique de Droit Français et Etranger XXII, 1943, págs. 1-43.

ESMEIN, A., Le délit d'adultère à Rome et la loi Julia de adulteriis coercendis. Etude de droit pénal, Paris, 1878.

FIELD, J.A., «The purpose of the lex Iulia and Papia Poppaea», Classical Journal XL, 1944-45, págs. 398-416.

GARCIA GARRIDO, M., «El Senadoconsulto Veleyano», Anuario de Historia del Derecho Español XXVII-XXVIII, 1957-58, págs. 1.268-1.271.

- Ius Vxorium. El régimen patrimonial de la mujer casada en el Derecho Romano, Roma-Madrid, 1958.

GIDE, P., Etude sur la condition privée de la femme dans le droit ancien et moderne et en particulier sur le sénatusconsulte Velléien, Paris, 1885.

HERRMANN, C., Le rôle judiciaire et politique des femmes sous la République romaine, Bruxelles, 1964.

JONKERS, E.J., «A few reflections on the backgroung of Augustus's Laws to increase the birth-rate», Symbolae ad Jus et Historiam Antiquitatis Pertinentes Julio Christiano van Oven dedicatae, Leiden, 1946, págs. 285-296.

KASER, M., «Die Rechtsgrundlage der actio rei uxoriae», $R e$ vue Internationale des Droits de l'Antiquité II (Mélanges Fernand De Visscher, 1), 1949, págs. 511-550.

KUEBLER, B., «Ueber das Ius Liberorum der Frauen und die Vormundschaft der Mutter», Zeitschrift der SavignyStiftung für Rechtsgeschichte. Romanistische Abteilung XXX, 1909, págs. 154-183 y XXXI, 1910, págs. 176-195.

LAPRAT, R., «Le rôle économique et les prérogatives de la femme mariée dans l'ancien droit romain», Mélanges économiques dédiés à René Gonnard, Paris, 1946, págs. 173-195.

LAURIA, M., Matrimonio-dote in diritto romano, Napoli, 1952.

MEDICUS, D., Zur Geschichte des Senatus consultum Velleianum, Köln-Graz, 1957.

MEINHART, M., Die Senatusconsulta Tertullianum und Orfizianum in ihrer Bedeutung für das Klassische Römische Erbrecht, Graz-Wien-Köln, 1967.

PICINELLI, F., «La evoluzione storico-giuridica del divorzio in Roma da Romolo ad Augusto», Archivio Giuridico XXXIV, 1885, págs. 424-472.

ROBLEDA, O., El matrimonio en Derecho Romano, Roma, 1970.

ROTONDI, G., Leges publicae populi romani, reimp. Hildesheim, 1966.

SANFILIPO, C., «Di una interpretazione giurisprudenziale di senatoconsulti Orfiziano e Tertulliano», Festschrift Fritz Schulz I, Weimar, 1951, págs. 364-372.

SCHULZ, F., Classical Roman Law, Oxford, 1951.

SHELING, E., «Das Strafsystem der lex Julia de adulteriis», Zeitschrift der Savigny-Stiftung für Rechtsgeschichte. Romanistische Abteilung IV, 1883, págs. 160-163. 
SOLAZZI, S., "Console e pretore urbano nella datio tutoris», Archivio Giuridico LXXXV, 1921, págs. 278-288.

- «In tema di divorzio», Bullettino dell'Istituto di Diritto Romano XXXIV, 1925, págs. 1-28.

- «Studi sul divorzio», Bullettino dell'Istituto di Diritto Romano XXXIV, 1925, 295-319.

TALAMANCA, M., «La storia del S. C. Velleiano, Labeo IV, 1958, págs. 99-111.

TAUBENSCHLAG, R., Vormundschaftsrechtliche Studien. Beiträge zur Geschichte des römischen und griechischen Vormundschaftsrechts, Leipzig-Berlin, 1913.
VOGT, H., Studien zum Senatus consultum Velleianum, Bonn, 1952.

VOLTERRA, E., La conception du mariage d'après les juristes romains, Padova, 1940.

- Istituzioni di diritto privato romano, Roma, 1972.

WATSON, A., «The Divorce of Carvilius Ruga», Tijdschrift voor Rchtsgeschiedenis XXXIII, 1965, págs. 38-50.

- Roman Private Law around 200 B. C., Edinburgh, 1971.

WOLFF, H.J., «Zur Stellung der Frau im Klassischen römischen Dotalrecht», Zeitschrift der Savigny-Stiftung für Rechtsgeschichte. Romanistische Abteilung LIII, 1933, págs. 297-371. 